GRASAS Y ACEITES 68 (2)

April-June 2017, e193

ISSN-L: 0017-3495

doi: http://dx.doi.org/10.3989/gya.1051162

\title{
Methodology for predicting oily mixture properties in the mathematical modeling of molecular distillation
}

\author{
M.F. Gayol ${ }^{\mathrm{a}}$, M.C. Pramparo ${ }^{\mathrm{a}}$ and S.M. Miró Erdmann ${ }^{\mathrm{b}, \bowtie}$ \\ ${ }^{a}$ Facultad de Ingeniería, Universidad Nacional de Rio Cuarto, Córdoba, Argentina \\ ${ }^{b}$ Facultad de Ingeniería y Ciencias Agropecuarias, Universidad Nacional de San Luis, San Luis, Argentina \\ ${ }^{\bowtie}$ Corresponding author: smmiro@unsl.edu.ar
}

Submitted: 18 October 2016; Accepted: 06 March 2017

SUMMARY: A methodology for predicting the thermodynamic and transport properties of a multi-component oily mixture, in which the different mixture components are grouped into a small number of pseudo components is shown. This prediction of properties is used in the mathematical modeling of molecular distillation, which consists of a system of differential equations in partial derivatives, according to the principles of the Transport Phenomena and is solved by an implicit finite difference method using a computer code. The mathematical model was validated with experimental data, specifically the molecular distillation of a deodorizer distillate (DD) of sunflower oil. The results obtained were satisfactory, with errors less than $10 \%$ with respect to the experimental data in a temperature range in which it is possible to apply the proposed method.

KEYWORDS: Modeling; Molecular distillation; Oily mixtures; Properties

RESUMEN: Metodología para la predicción de propiedades de mezclas oleosas en el modelado matemático de la destilación molecular. Se presenta una metodología para la predicción de las propiedades termodinámicas y de transporte de mezclas oleosas multicomponentes, en la cual se agrupan los diferentes componentes de la mezcla en un número reducido de pseudocomponentes. Esta predicción de propiedades se utiliza en el modelado matemático de la destilación molecular que consta de un sistema de ecuaciones diferenciales en derivadas parciales, según los principios de los fenómenos de transporte y se resuelve mediante un método implícito de diferencias finitas mediante un código computacional. El modelo matemático fue validado con datos experimentales, específicamente de la destilación molecular de un destilado de desodorización (DD) de aceite de girasol. Los resultados obtenidos fueron satisfactorios, con un error menor al $10 \%$ en un rango de temperaturas.

PALABRAS CLAVE: Destilación molecular; Mezclas oleosas; Modelado; Propiedades

ORCID ID: Gayol MF http://orcid.org/0000-0001-9564-1983, Pramparo MC http://orcid.org/0000-0002-7203-6673, Miró Erdmann SM http://orcid.org/0000-0002-9396-8111

Citation/Cómo citar este artículo: Gayol MF, Pramparo MC, Miró Erdmann SM. 2017. Methodology for predicting oily mixture properties in the mathematical modeling of molecular distillation. Grasas Aceites $\mathbf{6 8}$ (2), e193. http:// dx.doi.org/10.3989/gya.1051162

Copyright: (C) 2017 CSIC. This is an open-access article distributed under the terms of the Creative Commons Attribution (CC-by) Spain 3.0 License. 


\section{INTRODUCTION}

The properties involved in the mathematical model of falling film molecular distillation are density, viscosity, heat capacity, vapor pressure, thermal conductivity, and enthalpy of vaporization and the mass diffusivity of the components of the distilled mixture. In order to perform the simulation of molecular distillation of a mixture, equations that correlate the physical, thermodynamic and transport properties of the pure components constituting the mixture with temperature are needed. These equations can be estimated from the physical constants of each pure species, such as the molecular weight, the critical properties, the normal boiling temperature, the melting temperature and the acentric factor. However, in some mixtures the components are numerous and have the distinction of having similarities in groups. Such is the case of the deodorization distillates (DD), which have groups of triglycerides, diglycerides, monoglycerides, fatty acids and others.

Deodorization is an operation of heat and mass transfer that removes substances that give flavors and undesirable odors to vegetable oils. It is one of the final stages in the process of refining vegetable oils. From this operation, together with substances that produce undesirable odors, the DD is obtained, which comprises free fatty acids, tocopherols, sterols, squalene, mono and diglycerides, some triglycerides, heavy hydrocarbons and other minor components. The DD is mixed with effluent streams from the refining process or sold with low added value to industries that recover the valuable components (Naz et. al., 2014).

The molecular distillation operation is a separation technique used in the purification of low vapor pressure, high molecular weights or thermo labile liquid compounds. It is based on the evaporation of the components of a mixture in the form of a falling film, in contact with a heated surface and a following condensation on a close cold surface. As shown in Figure 1, feed enters in the top of the equipment of molecular distillation, the product resulting from steam condensation descends once in contact with a cooled wall, which is called distillate. The stream that does not evaporate is called residue.

The main characteristic of this operation is its working pressure of $10^{-4}$ to $10^{-7} \mathrm{~atm}$. At these pressures the relative volatility of the components increases and the operating temperature can be reduced to values lower than the conventional distillation temperature (Micov et al., 1997), allowing the separation of compounds that at higher temperatures are denatured or degraded.

Under these conditions, high evaporation rates occur and the residence time of the distilled mixture in the process is reduced, avoiding thermal decomposition of the components and performing

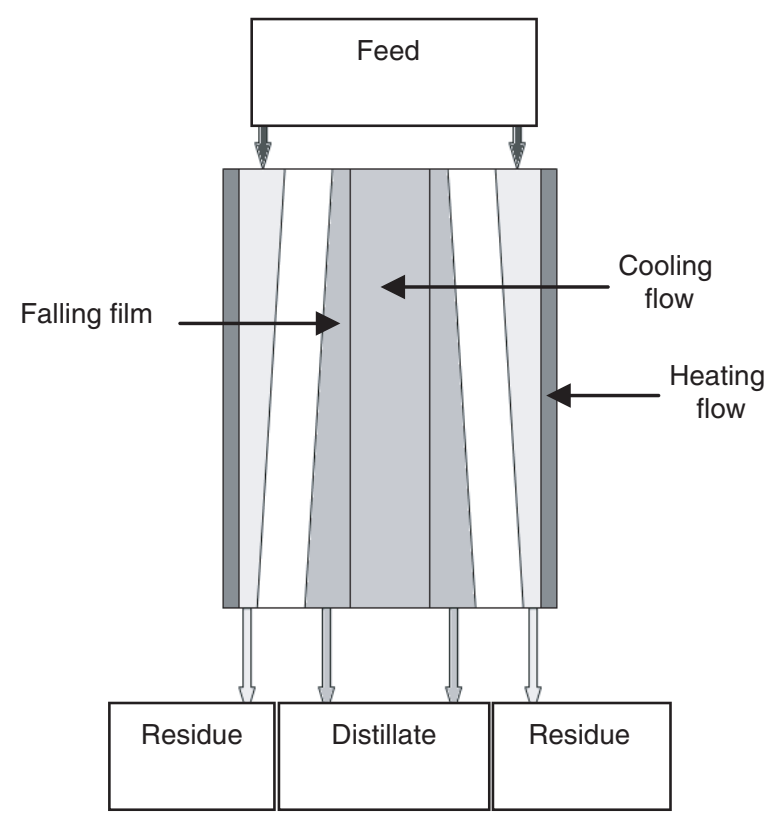

FIGURE 1. Phase distribution scheme of a falling film molecular distiller.

a separation at technologically acceptable speeds (Perry and Hecker, 1951). The degree of separation achieved in a molecular distillation process is a function of the relative volatilities of the components and the transport resistances in the liquid phase and its interaction with the intrinsic interfacial resistance of molecular kinetics. When a liquid mixture is evaporated, the vapor-liquid interface is cooled and the composition of the most volatile species decreases. This leads to the existence of driving forces for diffusive mass and heat transfer. The evaporation flow introduces a convective transport that is combined with the movement of the product to evaporate. All these resistances affect the evaporation rate and the product purity (Bose and Palmer, 1984). Preheating the feed up to a temperature near that of the evaporation surface temperature increases the efficiency of the operation (Cvengros et al., 2000).

Rossi et al. (2014) modeled this operation by artificial neural networks to represent the process of concentration by molecular distillation of omega-3 from squid oil.

We have studied this operation for the recovery of squalene from amaranth oil (Babeanu et al., 2016), the purification of dodecanoic acid (Yu et al., 2015) and the production of monoacylglycerols from sardine oil (Garcia Solaesa et al., 2016), among others.

The literature provides data on the thermodynamic and transport properties of the components of oils but does not do so in the case of the numerous mixtures of these components that can be found in nature. In this work, an indirect methodology is presented to estimate the properties of these mixtures through the application of a mathematical 
model of molecular distillation. The methodology consists of estimating the properties of the oil mixture from appropriate equations and then validating these results through the comparison of the data obtained from the mathematical model presented with experimental results of the molecular distillation of said mixture.

\section{METHODOLOGY}

\subsection{Model description}

The main part of the molecular distiller consists of two concentric cylinders; the annular hole between them is the space in which distillation occurs. The inner surface of the outer cylinder constitutes the heating surface and the outer surface of the inner cylinder constitutes the condensing surface. The evaporator cylinder is heated by a thermal fluid and the condenser cylinder is provided with a circuit of a refrigerant flow. The feed enters from the top of the heating cylinder and a film on the heating surface is produced by a system of liquid dispersion. As the film descends, it decreases in thickness because the components of the mixture are volatilized; its temperature increases and the concentrations of the species are modified, resulting in a residue which is rich in the less volatile components of the mixture. The vapors generated on the surface of the liquid film are condensed upon reaching the surface of the condenser cylinder; thus, the new liquid phase descends and leaves the molecular distillation as a distillate rich in the more volatile components of the mixture. The initial thickness of the film is in the order of the tenth of a millimeter, while the cylinder radius is in the order of centimeters (Micov et al., 1997).

To establish the model of the falling film for molecular distillation of an oily mixture it is supposed that the geometry is flat. The film descends with laminar flow by gravity in the positive direction of the $y$ coordinate, varying in thickness, $\mathrm{h}$, in the $\mathrm{z}$ coordinate. The operation is carried out at steady state and that the fluid is incompressible. The velocity, temperature and composition of the falling film vary in thickness and along the cylinder, therefore so do the physical properties, thermodynamic and transport properties of the mixture, to a vertical position and are considered as a function of average molar ratio, $\mathrm{x}_{\mathrm{mk}}$, of each species $\mathrm{k}$ and the average temperature $\mathrm{T}_{\mathrm{m}}$ in that position. The evaporation rate in the molecular distillation is calculated using an approach that was presented by Langmuir (1913), and obtained by studying the vapor pressure of tungsten filaments:

$$
\phi_{k}(T)=\frac{P v_{k}(T)}{\sqrt{2 \pi R M_{k} T}}
$$

where $\phi_{k}$ is the boiling speed of the $\mathrm{k}$ species in a vacuum, $T$ is the absolute temperature, $P v_{k}$ is the vapor pressure, $M_{k}$ is the molar weight and $R$ is the universal gas constant.

\subsection{Constitutive equations of the mathematical model}

When solving the balance of momentum of the descending film (Bird et al., 1960) applying boundary conditions:

- Variation of the vertical component of the velocity with respect to the horizontal dimension, at the surface of the film $\mathrm{dv}_{\mathrm{y}} / \mathrm{dz}=0$

- Vertical component of velocity on the wall $\mathrm{v}_{\mathrm{y}}=0$

equation [2] is obtained:

$$
v_{y}(z, y)=\frac{\rho(y) g_{y} h(y)^{2}}{2 \mu(y)}\left[2 \frac{z}{h(y)}-\left(\frac{z}{h(y)}\right)^{2}\right]
$$

where $\mu$ is the dynamic viscosity of the mixture, $g_{v}$ is the $y$ component of the gravity acceleration, $\rho$ is the density of the mixture, $h$ is the thickness of the film in evaporation, $y$ is the vertical dimension, $z$ is the horizontal dimension and $v_{y}$ is the velocity of the descending film.

Applying an energy balance, considering that in the gas-liquid interface energy transfer is performed by a conduction-evaporation mechanism, the problem is defined by the system of equations [3].

$$
\left\{\begin{array}{l}
\rho C p v_{y} \frac{\partial T}{\partial y}=\lambda \frac{\partial^{2} T}{\partial z^{2}} \\
T=T_{F} \quad 0 \leq z \leq h \quad y=0 \\
T=T_{W} \quad z=0 \quad y>0 \\
-\left.\lambda \frac{\partial T}{\partial z}\right|_{z=h}=\sum_{k=1}^{N} \Delta H v_{k} x_{S k} \phi_{k} \quad z=h \quad y>0
\end{array}\right.
$$

where $C p$ is the heat capacity of the mixture and $\lambda$ is its thermal conductivity. $T_{F}$ is the feed temperature of the oil mixture, $T_{W}$ is the surface temperature of the film adhered to the heater wall, $\Delta H v_{k}$ is the enthalpy of vaporization and $x_{S k}$ is the molar fraction in the evaporation surface. Solving the problem of boundary value [3] allows obtaining the surface temperatures in the falling film.

Setting out the mass balance with the condition that in the gas-liquid interface there is no re-evaporation and the molar composition is $x_{S k}$ then the 
flow density of $k$ species in $z=h$ is given by the $x_{S k} \phi_{k}$ product and the system of equations is obtained [4].

$$
\left\{\begin{array}{l}
v_{y} \frac{\partial x_{k}}{\partial y}=D_{k m} \frac{\partial^{2} x_{k}}{\partial z^{2}} \\
x_{k}=x_{F k} \quad z>0 \quad y=0 \\
\frac{\partial x_{k}}{\partial z}=0 \quad z=0 \quad y>0 \\
\frac{\partial x_{k}}{\partial z}=\frac{x_{S k}}{C D_{k m}}\left(\sum_{k=1}^{N} x_{S k} \phi_{k}-\phi_{k}\right) z=h \quad y>0
\end{array}\right.
$$

where $D_{k m}$ is the diffusivity of the species in the mixture $k, C$ is the mixture molar concentration and $x_{F k}$ is the feed molar fraction.

The mathematical model is completed by equations to estimate the physical, thermodynamic and transport properties, which depend on the temperature of the mixture compounds based on their physical constants, and the oily mixture based on the properties of each compound. Using the Joback method of group contribution, the physical constants of the pure compounds are obtained and the acentric factor value is calculated with the Ambrose-Walton equation. The mixture density is calculated from the densities of the pure compounds by the Spencer-Danner-Li mixing rule. The density of a pure compound, at a temperature $T$, is estimated by the Rackett method. The heat capacity of the mixture is calculated assuming an ideal mixture and the heat capacity of the pure compound is calculated by the Ruzicka-Domalski method. The viscosity of the mixture is calculated by the Kendall and Monroe (Perry and Chilton, 1963) equation and the viscosity of a pure species is calculated according to the Hsu method. The thermal conductivity of the mixture is calculated using the Li equation and the thermal conductivity of a pure species by the Missenard method. The vaporization enthalpy is calculated with the correlation of corresponding states. The vapor pressure is calculated by the Riedel method. The WilkeChang equation and the Perkins-Geankoplis equation are used to calculate the diffusivity (Perry y Green, 2008).

To solve the model containing equations [2], [3] and [4] an implicit finite difference method is used. The software for modeling the molecular distillation was developed in a MATLAB 7.0 environment. This was coupled to the calculation of physical thermodynamic and phenomenological properties, which varying with temperature should be estimated simultaneously with the nodal resolution finite difference method.

\subsection{Proposed methodology for predicting the properties}

The oily mixture to consider, whose properties are estimated in this study, is the sunflower oil DD. Since the lipid mixture feed to the process has a significant amount of compounds which are not all detected chromatographically, they are simulated by grouping them. Each group consists of substances with similar characteristics, and represented by the most abundant or representative of the group.

Based on the modelling sample, the following are considered pseudo components of the feed components:

A: Mixture of fatty acids: Martinello et al. (2008) reported that fatty acids are present in the DD of sunflower oil with the following composition: $11.31 \%$ palmitic acid (hexadecanoic acid), 6.02\% stearic acid (octadecanoic acid), 21.61\% oleic acid (cis-9-octadecenoic acid) and 59.88\% linoleic acid (9Z, 12Z -9,12-octadecadienoic acid). A mixture of the major fatty acids was considered, maintaining these mass ratios.

B: Monoglyceride mixture: A mixture of monoglycerides in the same ratio as the fatty acids was considered.

C: Mixture of total tocopherols and total sterols, with the compositions of total tocopherols and sterols determined chromatographically, reported by Martinello et al. (2008). The tocopherols were represented by the a-tocoferol ((2R)-2,5,7,8tetrametil-2-[(4R,8R)-4,8,12-trimetiltridécil]-3,4dihydrocroman-6-ol) and the sterols by the sitosterol (17-(5-Ethyl-6-methylheptan-2-yl)-10,13-dimethyl$2,3,4,7,8,9,11,12,14,15,16,17$-dodecahydro-1Hcyclopenta[a]phenanthren-3-ol).

D: Mixture of triglycerides: a mixture of triglycerides in the same ratio as the fatty acids was considered.

\section{RESULTS AND DISCUSSION}

\subsection{Experimental validation}

The validation of the mathematical model and the methodology presented was performed by comparing the experimental data obtained in the working group (Martinello et al., 2008) with the simulation results. Experimental data were obtained as derived from one-stage molecular distillation using a KDL4 of UIC equipment with the following operating conditions: feed flow of $1.9 \mathrm{ml} / \mathrm{min}$, feed temperature at $45^{\circ} \mathrm{C}$, condenser temperature at $25^{\circ} \mathrm{C}$, pressure of $10^{-5} \mathrm{~atm}$. 
Table 1 shows the composition of the raw material of the molecular distillation, where the major components of sunflower oil DD are presented, Naz et al. (2014) reported similar data. Feeding from the distillation of the simulated oily mixture has the $w_{F K}$ mass compositions of the $\mathrm{A}, \mathrm{B}, \mathrm{C}$ and D pseudo components, which are shown in Table 2.

Table 3 shows the experimental results and simulation results, performed at different temperatures, with the corresponding percentage relative error based on the experimental data. The percentage of relative error for the distillate is less than $1 \%$ in all cases. The percentage of relative error for the A composition in the distillate does not exceed $10 \%$. The percentage error for the species composition of the residue $\mathrm{C}$ is greater than $10 \%$ at temperatures of 130 and $140{ }^{\circ} \mathrm{C}$

\subsection{Performance of the modeling molecular distiller}

Figures 2 to 5 show the results obtained by resolving the model.

In Figure 2 the variation of the compositions of the mixture species on the surface of the falling

TABLE 1. Sunflower oil DD composition

\begin{tabular}{lc}
\hline Components & Mass\% \\
\hline$\alpha$-tocopherol & 3.87 \\
$\delta$-tocopherol & 1.17 \\
$\beta$ and $\gamma$-tocopherol & 3.72 \\
Total tocopherols & $\mathbf{7 . 7 6}$ \\
$\beta$-sitosterol & 4.12 \\
campesterol & 1.65 \\
stigmasterol & 1.68 \\
Total sterols & $\mathbf{7 . 4 5}$ \\
Palmitic Acid & 3.97 \\
Estearic Acid & 2.11 \\
Oleic Acid & 7.58 \\
Linoleic Acid & 21.00 \\
Others & 0.41 \\
Total Acidity (as oleic acid) & $\mathbf{3 5 . 0 8}$ \\
Total Mono and Diglicerides & $\mathbf{2 6 . 9 0}$ \\
Total Triglicerids & $\mathbf{2 2 . 8 1}$ \\
\hline
\end{tabular}

TABLE 2. Compositions of the sunflower oil DD model

\begin{tabular}{lc}
\hline Component & $\boldsymbol{w}_{\boldsymbol{F}}[\mathbf{K g} / \mathbf{K g}]$ \\
\hline A: Mixture of fatty acids & 0.351 \\
B: Monoglyceride mixture & 0.269 \\
C: Mixture of total tocopherols and & 0.152 \\
total sterols & 0.228 \\
D: Mixture of triglycerides & \\
\hline
\end{tabular}

film is shown. It can be observed that the compositions of species A and B decrease along the cylinder heater, since they are the species that pass to the vapor phase in greater proportions, as they have higher vapor pressure. Therefore, the compositions of species $\mathrm{C}$ and $\mathrm{D}$ increase in the film surface. A similar behavior was presented by Pramparo for a mixture of two components (Martinello, 2008).

In Figure 3 the velocity profiles are shown and a marked dependence with the $z$ coordinate is noticeable. As stipulated in the boundary conditions, both the velocity at the wall and the velocity gradients in the liquid-gas interface are zero.

TABLE 3. Experimental results and simulation results of molecular distillation of sunflower oil DD (mass \%).

Experimental results are expressed as pseudo components.

$T_{w}$ : distillation temperature, $D / F^{o} \%$ : percentage relationship between distillate and feed

\begin{tabular}{|c|c|c|c|}
\hline & Experimental & Simulation & $\%$ Error \\
\hline \multicolumn{4}{|l|}{$T_{W}=100^{\circ} \mathrm{C}$} \\
\hline$D / F \%$ & 27.90 & 27.88 & 0.07 \\
\hline $\begin{array}{l}\text { Fatty acids in the } \\
\text { distillate }(A \%)\end{array}$ & 60.20 & 54.25 & 9.88 \\
\hline $\begin{array}{l}\text { Tocopherols and } \\
\text { sterols in the } \\
\text { residue (C\%) }\end{array}$ & 21.10 & 20.39 & 3.36 \\
\hline \multicolumn{4}{|l|}{$T_{W}=110^{\circ} \mathrm{C}$} \\
\hline$D / F \%$ & 38.47 & 38.49 & 0.05 \\
\hline $\begin{array}{l}\text { Fatty acids in the } \\
\text { distillate }(A \%)\end{array}$ & 57.71 & 52.87 & 8.38 \\
\hline $\begin{array}{l}\text { Tocopherols and } \\
\text { sterols in the } \\
\text { residue (C\%) }\end{array}$ & 24.72 & 22.76 & 7.94 \\
\hline \multicolumn{4}{|l|}{$T_{W}=120^{\circ} \mathrm{C}$} \\
\hline$D / F \%$ & 50.20 & 50.21 & 0.02 \\
\hline $\begin{array}{l}\text { Fatty acids in the } \\
\text { distillate }(A \%)\end{array}$ & 52.30 & 51.09 & 2.30 \\
\hline $\begin{array}{l}\text { Tocopherols and } \\
\text { sterols in the } \\
\text { residue (C\%) }\end{array}$ & 24.28 & 25.54 & 5.20 \\
\hline \multicolumn{4}{|l|}{$T_{W}=130^{\circ} \mathrm{C}$} \\
\hline$D / F \%$ & 60.00 & 60.15 & 0.25 \\
\hline $\begin{array}{l}\text { Fatty acids in the } \\
\text { distillate }\left(A^{\circ} \%\right)\end{array}$ & 46.66 & 49.24 & 5.54 \\
\hline $\begin{array}{l}\text { Tocopherols and } \\
\text { sterols in the } \\
\text { residue (C\%) }\end{array}$ & 24.06 & 27.50 & 14.29 \\
\hline \multicolumn{4}{|l|}{$T_{W}=140^{\circ} \mathrm{C}$} \\
\hline$D / F \%$ & 64.10 & 64.41 & 0.49 \\
\hline $\begin{array}{l}\text { Fatty acids in the } \\
\text { distillate }\left(A^{0} \%\right)\end{array}$ & 49.99 & 48.13 & 3.71 \\
\hline $\begin{array}{l}\text { Tocopherols and } \\
\text { sterols in the } \\
\text { residue (C\%) }\end{array}$ & 21.96 & 26.96 & 21.96 \\
\hline
\end{tabular}




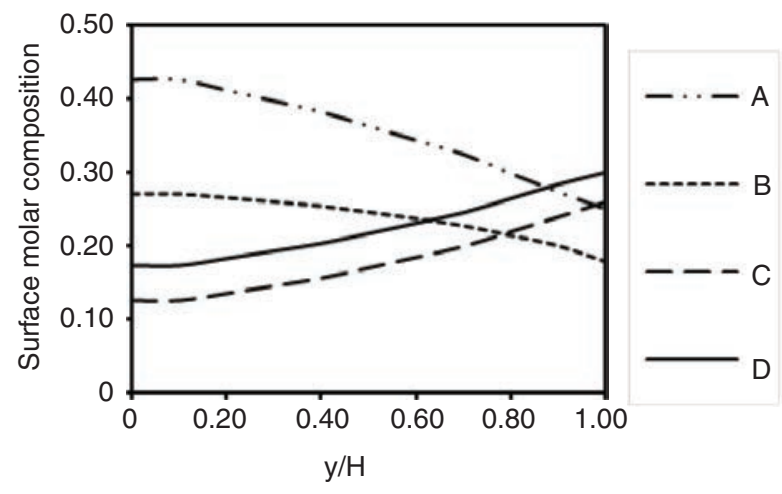

FIGURE 2. Surface molar composition of the falling film along the molecular distiller at a distillation temperature of $110^{\circ} \mathrm{C}$. A: Mixture of fatty acids, B: Monoglyceride mixture, C: Mixture of total tocopherols and total sterols, D: Mixture of triglycerides. $\mathrm{y} / \mathrm{H}$ : dimensionless length.

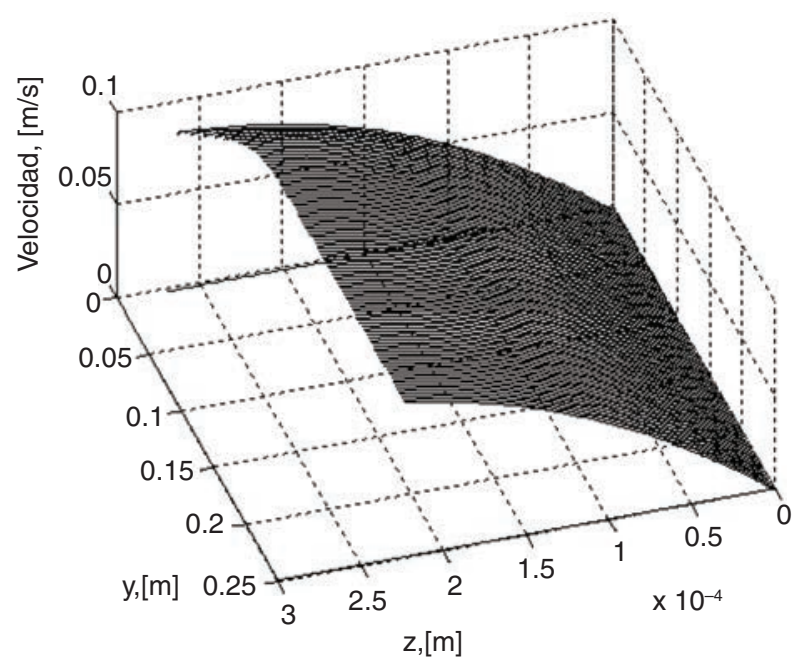

FIGURE 3. Velocity profiles in a falling film at a distillation temperature of $110^{\circ} \mathrm{C}$. $y$ : length of falling film, z: thickness of falling film.

The profiles present a parabolic type, characteristic of the laminar flow of the liquid mixture throughout the distiller.

In Figure 4 the temperature profiles can be seen. Since $y=0 m$ to $y=0.05 \mathrm{~m}$, approximately, it can be seen that the profiles are variable, ranging from the temperature of the heating wall, at $z$ $=0 \mathrm{~m}$, until the surface temperature of the falling film, $z=h$.

In Figure 5 the composition of the profiles of the A species are shown. The molar fraction of A decreases from the inlet to the cylinder heater. Significant variations in the concentration profiles along the $\mathrm{z}$ coordinate, near the feed area, are not observed.

The theoretical concepts used in the mathematical model and the methodology used for predicting

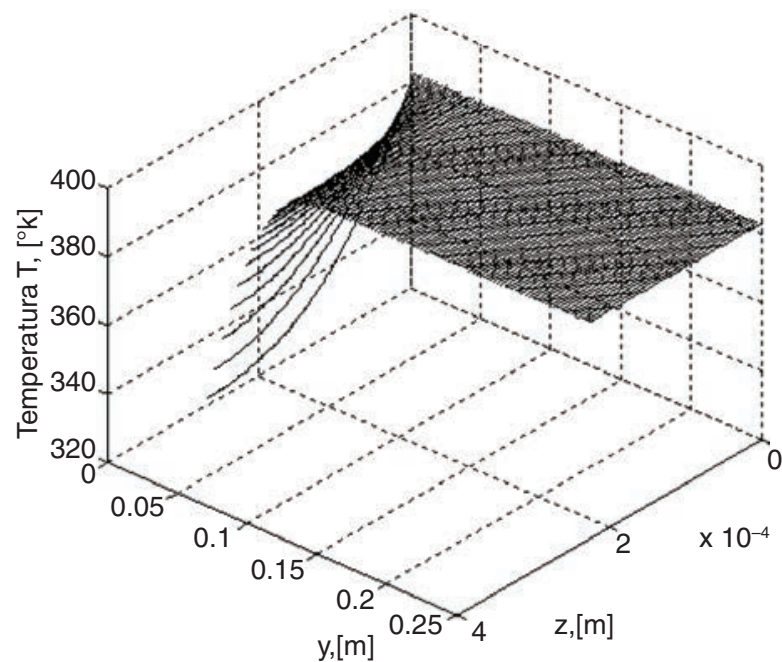

FIgURE 4. Temperature profiles of the falling film at a distillation temperature of $110^{\circ} \mathrm{C}$. $y$ : length of falling film, $\mathrm{z}$ : thickness of falling film.

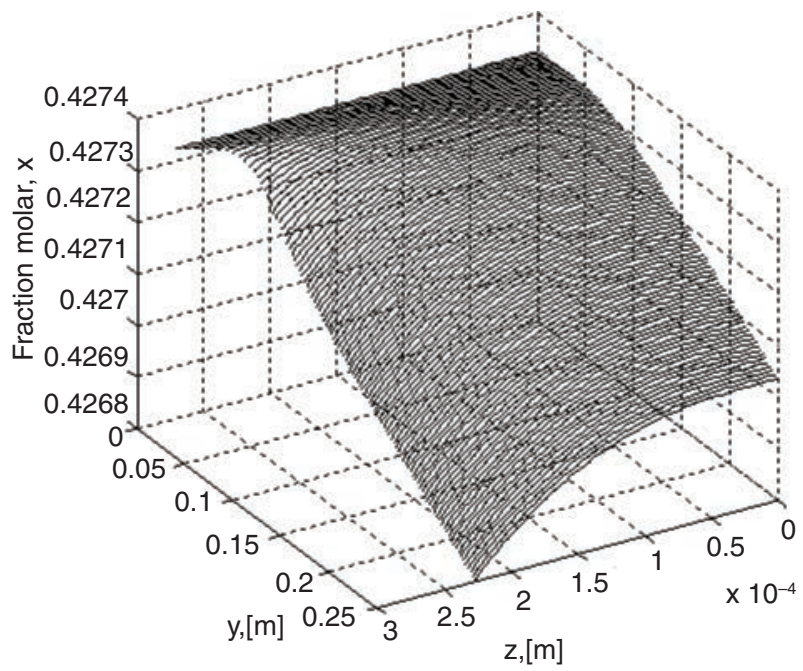

Figure 5. Composition profiles for the A species in the falling film at a distillation temperature of $110^{\circ} \mathrm{C}$. A: Mixture of fatty acids, $y$ : length of falling film, $z$ : thickness of falling film.

properties reflect the constant and uniform behavior of the temperature variation, velocity and composition along the falling film. Several studies show this behavior and are in agreement with the conclusions reported by Rossi et al. (2014).

\section{CONCLUSIONS}

The proposed methodology and the mathematical model were validated with experimental data available in the working group. Contrasting errors of the model with experimental data are low in regards to the measured total mass or flows. Composition results have a higher error margin. 
The model allowed representation of the phenomena occurring in the molecular distillation operation, as well as the theoretical analysis of its performance, since is not possible to experimentally determine the internal variables of the equipment due to their complex operating characteristics.

The proposed methodology facilitates and solves the problem of complex mixtures with a high number of unknown components that are in a low proportion. From the obtained results it is concluded that this methodology is applicable in the temperature values in which the error does not exceed 10\%, for this particular case the errors obtained at temperatures greater than $130^{\circ}$ are not acceptable.

\section{ACKNOWLEDGMENT}

The authors would like to thank the Secretaría de Políticas Universitarias for supporting this research.

\section{REFERENCES}

Babeanu N, Nita S, Popa O, Ioan Marin D. 2016. Squalene recovery from amaranth oil by short path distillation. J. Biotechnol. 231, 10. http://dx.doi.org/10.1016/j. jbiotec.2016.05.200

Bose A, Palmer H. 1984. Influence of heat and mass transfer resistances on the separation efficiency in molecular distillations. Ind. Eng. Chem. Fundamen. 23, 459-465. http:// dx.doi.org/10.1021/i100016a014

Cvengros J, Lutisan J, Micov M. 2000. Feed temperature influence on the efficiency of a molecular evaporator.
Chem. Eng. J. 78, 61-67. http://dx.doi.org/10.1016/ S1385-8947(99)00159-X

García Solaesa A, Sanza M T, Falkeborgb M, Beltrána S, Guob Z. 2016. Production and concentration of monoacylglycerols rich in omega-3 polyunsaturated fatty acids by enzymatic glycerolysis and molecular distillation. Food Chem. 190, 960-967. http://dx.doi.org/10.1016/j. foodchem.2015.06.061

Langmuir I. 1913. The vapor pressure of metallic tungsten. Phys. Rev. 2, 329-342. https://doi.org/10.1103/PhysRev.2.329

Martinello M, Leone I, Pramparo M. 2008. Simulation of deacidification process by molecular distillation of deodorizer distillate. Latin. Am. Appl. Res. 38, 299-304.

Micov M, Lutisan J, Cvengros J. 1997. Balance equations for molecular distillation. Sep. Sci. Technol. 32, 3051-3066. http://dx.doi.org/10.1080/01496399708000795

Naz S, Sherazi ST, Talpur FN, Kara H, Uddin S, Khaskheli AR. 2014. Chemical characterization of canola and sunflower oil deodorizer distillates. Pol. J. Food Nutr. Sci. 64, 115120. https://doi.org/10.2478/pjfns-2013-0008

Perry RH, Chilton CH, Kirkpatrik SD. 1963. Perry's Chemical Engineers' Handbook. McGraw-Hill. New York. http:// dx.doi.org/10.1002/aic.690100303

Perry RH, Green DW. 2008. Perry's Chemical Engineers' Handbook. McGraw-Hill. New York.

Perry ES, Hecker JC. 1951. Distillation Under High Vacuum. in Weissberger (Ed.) Techniques of Organic Chemistry, vol. 4, Interscience Publishers, New York, pp. 495-602.

Rossi P, Gayol M F, Renaudo C, Pramparo MC, Nepote V, Grosso NR. 2014. The use of artificial neural network modeling to represent the process of concentration by molecular distillation of omega-3 from squid oil. Grasas Aceites 65, e052. http://dx.doi.org/10.3989/gya.0231141

$\mathrm{Yu}$ J, Yuan X, Zeng A. 2015. A novel purification process for dodecanedioic acid by molecular distillation. Chin. J. Chem. Eng. 23, 499-504. http://dx.doi.org/10.1016/j. cjche.2014.10.019 